\title{
High-frequency Oligonucleotides in Watermelon Expressed Sequenced Tag-unigenes Are Useful in Producing Polymorphic Polymerase Chain Reaction Markers among Watermelon Genotypes
}

\author{
Amnon Levi ${ }^{1}$ and William P. Wechter \\ U.S. Department of Agriculture, Agricultural Research Service, U.S. Vegetable Laboratory, 2700 \\ Savannah Highway, Charleston, SC 29414 \\ Karen R. Harris \\ U.S. Department of Agriculture, Agricultural Research Service, Crop Genetics and Breeding \\ Research Unit, 115 Coastal Way, Tifton, GA 31793
}

\begin{abstract}
Angela R. Davis
U.S. Department of Agriculture, Agricultural Research Service, 911 East Highway 3, Lane, OK 74555-0159
\end{abstract}

\begin{abstract}
Zhangjun Fei
Boyce Thompson Institute for Plant Research, Cornell University, Ithaca, NY 14853 and U.S. Department of Agriculture, Robert W. Holley Center for Agriculture and Health, Ithaca, NY 14853
\end{abstract}

\begin{abstract}
AdDitional Index words. Citrullus lanatus, HFO-TAG, RAPD, ISSR, DNA, phylogenetic
Abstract. In this study, we report a simple procedure for developing and using new types of polymerase chain reaction (PCR) primers, named "high-frequency oligonucleotides-targeting active genes" (HFO-TAG). The HFOTAG primers were constructed by first using a "practical extraction and report language" script to identify oligonucleotides $(8,9$, and 10 bases) that exist in high frequency in 4700 expressed sequence tag (EST)-unigenes of watermelon (Citrullus lanatus) fruit. This computer-based screening yielded 3162 oligonucleotides that exist 32 to 335 times in the 4700 EST-unigenes. Of these, 192 HFO-TAG primers (found 51 to 269 times in the 4700 EST-unigenes) were used to amplify genomic DNA of four closely related watermelon cultivars (Allsweet, Crimson Sweet, Charleston Gray, and Dixielee). The average number of DNA fragments produced by a single HFO-TAG primer among these four watermelon cultivars was considerably higher (an average of 5.74 bands per primer) than the number of fragments produced by intersimple sequence repeat (ISSR) or randomly amplified polymorphic DNA (RAPD) primers (an average of 2.32 or 4.15 bands per primer, respectively). The HFO-TAG primers produced a higher number of polymorphic fragments (an average of 1.77 polymorphic fragments per primer) compared with the ISSR and RAPD primers (an average of 0.89 and 0.47 polymorphic fragments per primer, respectively). Amplification of genomic DNA from 12 watermelon cultivars and two U.S. Plant Introductions with the HFO-TAG primers produced a significantly higher number of fragments than RAPD primers. Also, in PCR experiments examining the ability of primers to amplify fragments from a watermelon cDNA library, the HFO-TAG primers produced considerably more fragments (an average of 6.44 fragments per primer) compared with ISSR and RAPD primers (an average of 3.59 and 2.49 fragments per primer, respectively). These results indicate that the HFO-TAG primers should be more effective than ISSR or RAPD primers in targeting active gene loci. The extensive EST database available for a large number of plant and animal species should be a useful source for developing HFO-TAG primers that can be used in genetic mapping and phylogenic studies of important crop plants and animal species.
\end{abstract}

Although watermelon has a wide range of fruit phenotypes (including fruit size and shape, skin color and rind thickness, flesh color and texture, sugar content, and seed number, size, color, and shape), a narrow genetic base exists among American heirloom cultivars. The use of randomly amplified polymorphic DNA (RAPD) primers produced a low number of polymorphic markers among watermelon heirloom cultivars (Levi et al., 2001). In a

Received for publication 4 Nov. 2009. Accepted for publication 23 Apr. 2010. The use of trade names in this publication does not imply endorsement by the USDA of the products named or criticism of similar ones not mentioned.

We gratefully acknowledge the technical assistance of Laura Pence and Ellis Caniglia.

${ }^{1}$ Corresponding author. E-mail: amnon.levi@ars.usda.gov. recent study, 1309 RAPD primers were screened to identify polymorphic markers between two watermelon breeding lines whose progeny segregate for race 1 fusarium wilt resistance (caused by Fusarium oxysporum f. sp. niveum). Of these 1309 primers, only 75 polymorphic markers $(\approx 1$ polymorphism per 17 primers) were identified between these two breeding lines of watermelon (Harris et al., 2008 and K. Harris and A. Levi, unpublished data). The phenotypic diversity among watermelon cultivars could be the result of point mutations in genes controlling fruit quality (Levi et al., 2001, 2006b, 2009), which may not be readily detected by random primers. In fact, DNA polymorphism among watermelon cultivars could be detected with expressed sequence tag (EST)-polymerase chain reaction 
(PCR) and sequence-related amplified polymorphism (SRAP) markers when analyzed using dye-based capillary electrophoresis technologies that have the capability to detect single nucleotide differences (Levi et al., 2006b, 2009). The polymorphism revealed by capillary electrophoresis is often the result of a difference in a single or a few base pairs that cannot be detected by standard agarose gel electrophoresis (Levi et al., 2006b). Also, our experiments with amplified fragment length polymorphism (AFLP) markers analyzed by capillary electrophoresis produced higher polymorphism among watermelon cultivars than RAPD primers (Levi et al., 2004). However, mapping experiments indicated that most of the AFLP markers were clustered on several linkage groups and did not cover all regions of the watermelon genome (Levi et al., 2006b).

The new technologies developed in recent years for DNA sequencing have produced an extensive sequence database and have enabled the physical assembly of numerous plant and animal genomes (Wicker et al., 2009). Sequence data have been used for the development of simple sequence repeat (SSR) markers used in gene tagging (Gong et al., 2009; Katzir et al., 1996), as well as the development of single nucleotide polymorphism (SNP) markers (Ganal et al., 2009). Sequences with wide genomic distribution, like SSR motifs, have been useful for the development of genetic markers in a large number of plant genomes (Holland et al., 2001; Jarret et al., 1997; Katzir et al., 1996). Oligonucleotides that exist in high frequency in active gene sequences should be valuable anchors for producing polymorphic DNA markers and for genetic mapping and the identification of important gene loci in a large number of crop plants. We hypothesized that a bioinformatics approach could be used in identifying oligonucleotides that exist in high frequency in expressed genes. These oligonucleotides could then be used to design random yet species-targeted primers for the identification of polymorphic markers between closely related genotypes.

In a recent study, we constructed a cDNA library representing early, maturing, and ripe stages of the watermelon fruit. The fruit cDNA library was normalized and subtracted with cDNAs from young watermelon leaf (Levi et al., 2006a; Wechter et al., 2008). Over 8800 cDNA clones were sequenced and assembled into 4700 EST-unigenes. These EST-unigene sequences are available on the International Cucurbit Genomics Initiative website (2009). In this study, we searched for oligonucleotides $(8,9$, and $10 \mathrm{bp})$ that exist in high frequency in the 4700 watermelon EST-unigenes. We tested the potential of these oligonucleotides as PCR primers to produce polymorphic markers from genomic DNA of closely related heirloom watermelon cultivars (C. lanatus var. lanatus) and U.S. Plant Introductions (PIs) of C. lanatus var. lanatus and C. lanatus var. citroides. To substantiate the possibility that the high-frequency oligonucleotides-targeting active genes (HFO-TAG) primers are better suited than ISSR or RAPD primers to target active gene sequences, we also examined their ability to amplify fragments from a cDNA library representing watermelon fruit.

\section{Materials and Methods}

Plant material and isolation of DNA. Twelve heirloom cultivars that were previously shown to have a low rate of crosscultivar polymorphism when analyzed using standard RAPD primers (Levi et al., 2001) were selected for analysis. These cultivars are Allsweet, Crimson Sweet, Charleston Gray, Dixielee, Congo, Mickylee, Minilee, Sugar Baby, Jubilee, Black Diamond,
Calhoun Gray, and New Hampshire Midget. In addition, U.S. PI 203551 (C. lanatus var. lanatus) and PI 296341 (C. lanatus var. citroides) also were used for analysis. Seedlings of the watermelon cultivars and PIs were grown in the greenhouse at $26 / 20^{\circ} \mathrm{C}$ (day/night temperatures). Young leaves were collected from 2- to 3-week-old plants and were stored at $-80{ }^{\circ} \mathrm{C}$ for later DNA isolation. The DNA was isolated from the frozen leaves using the method described by Levi and Thomas (1999).

BIOINFORMATIC ANALYSIS FOR IDENTIFICATION OF PREVALENT SHORT SEQUENCES. An in-house computer script was written in practical extraction and report language (Perl) and was used to query for the most frequent 8- to10-bp oligonucleotides (GC content $>75 \%$ ) in the 4700 watermelon EST-unigenes published on the International Cucurbit Genomics Initiative (ICuGI) website (International Cucurbit Genomics Initiative, 2009). One-hundred ninety-two oligonucleotides with melting temperatures of 34 to $42{ }^{\circ} \mathrm{C}$ were selected for constructing the HFO-TAG primers that were tested in this study (Table 1).

RAPD AND ISSR PRIMERS. We used RAPD and ISSR primers as a comparative reference to assess the effectiveness of the HFO-TAG primers in amplifying watermelon genomic DNA. Forty-nine RAPD primers (with a GC content of $60 \%$ 90\%) were from the AK and AL RAPD primer sets (Operon Technologies, Alameda, CA), and the UBC 500 and 700 primer sets (University of British Columbia, Vancouver, BC, Canada). The ISSR primers (98 primers) were from the UBC 800 primer set.

DNA AMPLIFICATION CONDITIONS AND GEL ELECTROPHORESIS. The PCR reaction and thermal cycling conditions for HFOTAG primers selected in this study (Table 1) were as described for RAPD primers by Levi et al. (1993, 2001): The PCR reaction cocktail $(25 \mu \mathrm{L})$ contained $20 \mu \mathrm{M} \mathrm{NaCl}, 50 \mathrm{~mm}$ Tris$\mathrm{HCl}, \mathrm{pH} 9,1 \%$ Triton X-100, 0.01\% gelatin, $1.6 \mathrm{~mm} \mathrm{MgCl}_{2}$, $200 \mu \mathrm{M}$ each of dNTPs (Sigma-Aldrich, St. Louis), $100 \mu \mathrm{M}$ primer, 5 units of GoTaq ${ }^{\circledR}$ DNA polymerase (Promega, Madison, WI), and $7 \mathrm{ng}$ of template DNA. Amplifications were carried out for 40 cycles in a PTC-200 thermocycler (MJ Research, Watertown, MA) for $60 \mathrm{~s}$ to denature the DNA at $92{ }^{\circ} \mathrm{C}$, $70 \mathrm{~s}$ for primer annealing at $35,40,45,48,50,55$, or $60{ }^{\circ} \mathrm{C}$ [as determined for each primer in Table 1, based on primer melting temperature (Tm)], and $120 \mathrm{~s}$ for primer extension at $72{ }^{\circ} \mathrm{C}$. Amplification products were separated by electrophoresis in $1.4 \%$ agarose gel in $0.5 \times$ Tris borate buffer (Sambrook et al., 1989). Before loading on agarose gels, the DNA samples were stained with the EZ-Vision ${ }^{\mathrm{TM}}$-Three dye (Amresco, Solon, $\mathrm{OH})$. DNA fragments were visualized under ultraviolet light and were photographed using a still video system (Gel Doc 2000; Bio-Rad, Hercules, CA). The size of the amplification products was determined by comparison with a 1-kb DNA ladder (Gibco-BRL, Gaithersburg, MD).

COMPARISON OF AMPLICONS GENERATED USING HIGHLY SIMILAR HFO-TAG PRIMERS. Eight 8-mer primers differing at a single nucleotide at the $3^{\prime}$ or $5^{\prime}$ end, and a 9-mer primer differing at the last two nucleotides of the $3^{\prime}$ end (Table 2) were tested with DNA from a single watermelon cultivar (Charleston Gray). Amplification conditions and post-amplification DNA visualization were performed as described above.

PCR AMPLIFICATION CONDITIONS FOR HFO-TAG, ISSR, AND RAPD PRIMERS USING CDNA AS A TEMPLATE. The cDNA library was constructed previously using mRNA representing watermelon fruit of the heirloom cultivar Illiniwake Red (as described by Levi et al., 2006a). PCR amplification conditions of 
Table 1. The 192 high-frequency oligonucleotides-targeting active genes (HFO-TAG) primers that were tested in PCR experiments with watermelon DNA. Oligonucleotide frequency among the 4700 watermelon EST-unigenes (FRQ), number of nucleotide bases for each primer (B), GC content $(1=100 \%)$, melting temperature $(\mathrm{Tm})$, and annealing temperature (Ta) used in PCR reactions with genomic or cDNA templates. In addition, the total number of fragments (TF) and the number of polymorphic fragments (PF) produced by each of the HFO-TAG primers among the closely related watermelon cultivars Allsweet, Crimson Sweet, Charleston Gray, and Dixielee.

\begin{tabular}{|c|c|c|c|c|c|c|c|c|}
\hline Primer & Oligos & FRQ (no.) & B (no.) & $\mathrm{GC}$ & $\operatorname{Tm}\left({ }^{\circ} \mathrm{C}\right)$ & $\mathrm{Ta}\left({ }^{\circ} \mathrm{C}\right)$ & TF (no.) & PF (no.) \\
\hline$\overline{\mathrm{HFO}-1}$ & CGGCGGCG & 269 & 8 & 1 & 43 & 48 & 9 & 2 \\
\hline HFO-2 & CGCCGCCG & 269 & 8 & 1 & 43 & 48 & 8 & 2 \\
\hline HFO-3 & CCGCCGCC & 240 & 8 & 1 & 41.9 & 48 & 9 & 1 \\
\hline HFO-4 & GGCGGCGG & 240 & 8 & 1 & 41.9 & 48 & 7 & 2 \\
\hline HFO-5 & CCACCGCC & 172 & 8 & 0.875 & 34 & 40 & 15 & 1 \\
\hline HFO-6 & GGCGGTGG & 172 & 8 & 0.875 & 34 & 40 & 12 & 1 \\
\hline HFO-7 & GCCGCCGC & 170 & 8 & 1 & 43.5 & 50 & 9 & 2 \\
\hline HFO-8 & GCGGCGGC & 170 & 8 & 1 & 43.5 & 50 & 10 & 0 \\
\hline HFO-9 & CGGCGGAG & 159 & 8 & 0.875 & 34 & 40 & 10 & 3 \\
\hline HFO-10 & CTCCGCCG & 159 & 8 & 0.875 & 34 & 40 & 8 & 2 \\
\hline HFO-11 & GGCGGAGG & 144 & 8 & 0.875 & 32.6 & 40 & 9 & 3 \\
\hline HFO-12 & CCTCCGCC & 144 & 8 & 0.875 & 32.6 & 40 & 8 & 2 \\
\hline HFO-13 & TCCGCCGC & 140 & 8 & 0.875 & 38.4 & 45 & 3 & 1 \\
\hline HFO-14 & GCGGCGGA & 140 & 8 & 0.875 & 38.4 & 45 & 6 & 1 \\
\hline HFO-15 & CACCGCCG & 136 & 8 & 0.875 & 35.4 & 40 & 3 & 1 \\
\hline HFO-16 & CGGCGGTG & 136 & 8 & 0.875 & 35.4 & 40 & 9 & 1 \\
\hline HFO-17 & CGACGGCG & 132 & 8 & 0.875 & 35.9 & 40 & 8 & 1 \\
\hline HFO-18 & CGCCGTCG & 132 & 8 & 0.875 & 35.9 & 40 & 7 & 2 \\
\hline HFO-19 & TCGCCGCC & 127 & 8 & 0.875 & 38.4 & 45 & 2 & 1 \\
\hline HFO-20 & GGCGGCGA & 127 & 8 & 0.875 & 38.4 & 45 & 7 & 1 \\
\hline HFO-21 & CCGCCGCCG & 120 & 9 & 1 & 49.1 & 55 & 9 & 6 \\
\hline HFO-22 & CGGCGGCGG & 120 & 9 & 1 & 49.1 & 55 & 4 & 1 \\
\hline HFO-23 & ACGGCGGC & 119 & 8 & 0.875 & 39.1 & 45 & 9 & 2 \\
\hline HFO-24 & CCGCCACC & 119 & 8 & 0.875 & 34 & 40 & 9 & 0 \\
\hline HFO-25 & GGTGGCGG & 119 & 8 & 0.875 & 34 & 40 & 7 & 0 \\
\hline HFO-26 & GCCGCCGT & 119 & 8 & 0.875 & 39.1 & 45 & 7 & 0 \\
\hline HFO-27 & CCGCCGTC & 118 & 8 & 0.875 & 34.7 & 40 & 6 & 1 \\
\hline HFO-28 & GACGGCGG & 118 & 8 & 0.875 & 34.7 & 40 & 9 & 2 \\
\hline HFO-29 & CGCCGCCGC & 114 & 9 & 1 & 50.4 & 55 & 0 & 0 \\
\hline HFO-30 & GCGGCGGCG & 114 & 9 & 1 & 50.4 & 55 & 6 & 3 \\
\hline HFO-31 & CGCCGCCA & 105 & 8 & 0.875 & 39.1 & 45 & 5 & 0 \\
\hline HFO-32 & TGGCGGCG & 105 & 8 & 0.875 & 39.1 & 45 & 1 & 1 \\
\hline HFO-33 & CGCCGGAG & 104 & 8 & 0.875 & 34 & 40 & 5 & 2 \\
\hline HFO-34 & CTCCGGCG & 104 & 8 & 0.875 & 34 & 40 & 5 & 2 \\
\hline HFO-35 & GCCGCCGCC & 96 & 9 & 1 & 49.7 & 55 & 6 & 4 \\
\hline HFO-36 & GGCGGCGGC & 96 & 9 & 1 & 49.7 & 55 & 8 & 6 \\
\hline HFO-37 & CGGCGCCG & 92 & 8 & 1 & 40.9 & 45 & 4 & 3 \\
\hline HFO-38 & GCCGCCGG & 85 & 8 & 1 & 41.9 & 48 & 11 & 3 \\
\hline HFO-39 & CCGGCGGC & 85 & 8 & 1 & 41.9 & 48 & 9 & 1 \\
\hline HFO-40 & CCGCCTCC & 85 & 8 & 0.875 & 32.6 & 40 & 10 & 1 \\
\hline HFO-41 & GCGGTGGC & 85 & 8 & 0.875 & 35.8 & 40 & 6 & 1 \\
\hline HFO-42 & GCCACCGC & 85 & 8 & 0.875 & 35.8 & 40 & 6 & 1 \\
\hline HFO-43 & GGAGGCGG & 85 & 8 & 0.875 & 32.6 & 40 & 12 & 2 \\
\hline HFO-44 & CGCCGGCG & 84 & 8 & 1 & 40.9 & 45 & 1 & 1 \\
\hline HFO-45 & CGGCGACG & 84 & 8 & 0.875 & 35.9 & 40 & 7 & 1 \\
\hline HFO-46 & CGTCGCCG & 84 & 8 & 0.875 & 35.9 & 40 & 5 & 1 \\
\hline HFO-47 & GCCGCCAC & 83 & 8 & 0.875 & 35.8 & 40 & 14 & 2 \\
\hline HFO-48 & GTGGCGGC & 83 & 8 & 0.875 & 35.8 & 40 & 10 & 2 \\
\hline HFO-49 & GCGGCGGT & 82 & 8 & 0.875 & 39.1 & 45 & 5 & 1 \\
\hline HFO-50 & ACCGCCGC & 82 & 8 & 0.875 & 39.1 & 45 & 7 & 2 \\
\hline HFO-51 & TCGCCGCCG & 81 & 9 & 0.889 & 46.1 & 50 & 8 & 0 \\
\hline HFO-52 & CGGCGGCGA & 81 & 9 & 0.889 & 46.1 & 50 & 9 & 1 \\
\hline HFO-53 & GGTGGGGG & 81 & 8 & 0.875 & 30.6 & 35 & 7 & 0 \\
\hline HFO-54 & CCCCCACC & 81 & 8 & 0.875 & 30.6 & 35 & 8 & 2 \\
\hline
\end{tabular}


Table 1. Continued.

\begin{tabular}{|c|c|c|c|c|c|c|c|c|}
\hline Primer & Oligos & FRQ (no.) & B (no.) & GC & $\operatorname{Tm}\left({ }^{\circ} \mathrm{C}\right)$ & $\mathrm{Ta}\left({ }^{\circ} \mathrm{C}\right)$ & TF (no.) & PF (no.) \\
\hline HFO-55 & CCGCCGCT & 79 & 8 & 0.875 & 38.3 & 45 & 2 & 0 \\
\hline HFO-56 & AGCGGCGG & 79 & 8 & 0.875 & 38.3 & 45 & 3 & 0 \\
\hline HFO-57 & TCCGCCGCC & 77 & 9 & 0.889 & 45.3 & 50 & 12 & 3 \\
\hline HFO-59 & CGCCACCG & 77 & 8 & 0.875 & 35.4 & 40 & 2 & 1 \\
\hline HFO-60 & TCGGCGGC & 77 & 8 & 0.875 & 38.4 & 45 & 3 & 1 \\
\hline HFO-63 & GCCGGCGA & 77 & 8 & 0.875 & 38.4 & 45 & 8 & 1 \\
\hline HFO-64 & TCGCCGGC & 77 & 8 & 0.875 & 38.4 & 45 & 1 & 1 \\
\hline HFO-65 & TCCGGCGG & 75 & 8 & 0.875 & 36.7 & 45 & 0 & 0 \\
\hline HFO-66 & CCGCCGGA & 75 & 8 & 0.875 & 36.7 & 45 & 0 & 0 \\
\hline HFO-67 & GCCGCTGC & 74 & 8 & 0.875 & 36.8 & 45 & 1 & 0 \\
\hline HFO-68 & GCAGCGGC & 74 & 8 & 0.875 & 36.8 & 45 & 4 & 1 \\
\hline HFO-73 & GTCGCCGG & 72 & 8 & 0.875 & 34.7 & 40 & 6 & 0 \\
\hline HFO-74 & CCGGCGAC & 72 & 8 & 0.875 & 34.7 & 40 & 8 & 2 \\
\hline HFO-75 & CCGCCGGC & 71 & 8 & 1 & 41.9 & 45 & 3 & 0 \\
\hline HFO-76 & GCCGGCGG & 71 & 8 & 1 & 41.9 & 45 & 2 & 1 \\
\hline HFO-77 & CCTCCGCCG & 71 & 9 & 0.889 & 41.2 & 45 & 6 & 1 \\
\hline HFO-78 & CGGCGGAGG & 71 & 9 & 0.889 & 41.2 & 45 & 8 & 3 \\
\hline HFO-79 & CCACCCCC & 70 & 8 & 0.875 & 30.6 & 35 & 8 & 2 \\
\hline HFO-80 & GGGGGTGG & 70 & 8 & 0.875 & 30.6 & 35 & 9 & 1 \\
\hline HFO-81 & GGCGGAGGA & 70 & 9 & 0.778 & 36.9 & 40 & 13 & 4 \\
\hline HFO-82 & TCCTCCGCC & 70 & 9 & 0.778 & 36.9 & 40 & 5 & 0 \\
\hline HFO-83 & GGCGGCGC & 69 & 8 & 1 & 43.5 & 50 & 12 & 4 \\
\hline HFO-91 & CGGCGTCG & 68 & 8 & 0.875 & 35.9 & 40 & 7 & 2 \\
\hline HFO-92 & CGACGCCG & 68 & 8 & 0.875 & 35.9 & 40 & 8 & 1 \\
\hline HFO-93 & GCGACGGC & 67 & 8 & 0.875 & 36.4 & 40 & 7 & 1 \\
\hline HFO-94 & GCCGTCGC & 67 & 8 & 0.875 & 36.4 & 40 & 8 & 2 \\
\hline HFO-97 & GCCGTCGC & 67 & 8 & 0.875 & 36.4 & 40 & 3 & 1 \\
\hline HFO-95 & GGCGACGG & 66 & 8 & 0.875 & 34.7 & 40 & 9 & 2 \\
\hline HFO-96 & CCACCGGC & 66 & 8 & 0.875 & 34 & 40 & 5 & 2 \\
\hline HFO-102 & CCGTCGCC & 66 & 8 & 0.875 & 34.7 & 40 & 1 & 0 \\
\hline HFO-99 & CCACCGGC & 66 & 8 & 0.875 & 34 & 40 & 3 & 2 \\
\hline HFO-100 & CGGCGGCT & 66 & 8 & 0.875 & 38.3 & 45 & 3 & 1 \\
\hline HFO-98 & GGCGACGG & 66 & 8 & 0.875 & 34.7 & 40 & 4 & 2 \\
\hline HFO-103 & GCCGGTGG & 66 & 8 & 0.875 & 34 & 40 & 4 & 3 \\
\hline HFO-101 & GGTGGCCG & 66 & 8 & 0.875 & 34 & 40 & 5 & 0 \\
\hline HFO-105 & AGCCGCCG & 66 & 8 & 0.875 & 38.3 & 45 & 7 & 2 \\
\hline HFO-104 & CGGCCACC & 66 & 8 & 0.875 & 34 & 40 & 7 & 3 \\
\hline HFO-106 & CGCCGCCGCC & 64 & 10 & 1 & 55.3 & 60 & 4 & 0 \\
\hline HFO-107 & GGCGGCGGCG & 64 & 10 & 1 & 55.3 & 60 & 8 & 1 \\
\hline HFO-110 & GCTCCGCC & 64 & 8 & 0.875 & 34.4 & 40 & 0 & 0 \\
\hline HFO-108 & GGCGGAGC & 64 & 8 & 0.875 & 34.4 & 40 & 0 & 0 \\
\hline HFO-111 & CACCGGCG & 64 & 8 & 0.875 & 34.4 & 40 & 1 & 1 \\
\hline HFO-109 & CGCCGGTG & 64 & 8 & 0.875 & 35.4 & 40 & 2 & 2 \\
\hline
\end{tabular}


Table 1. Continued.

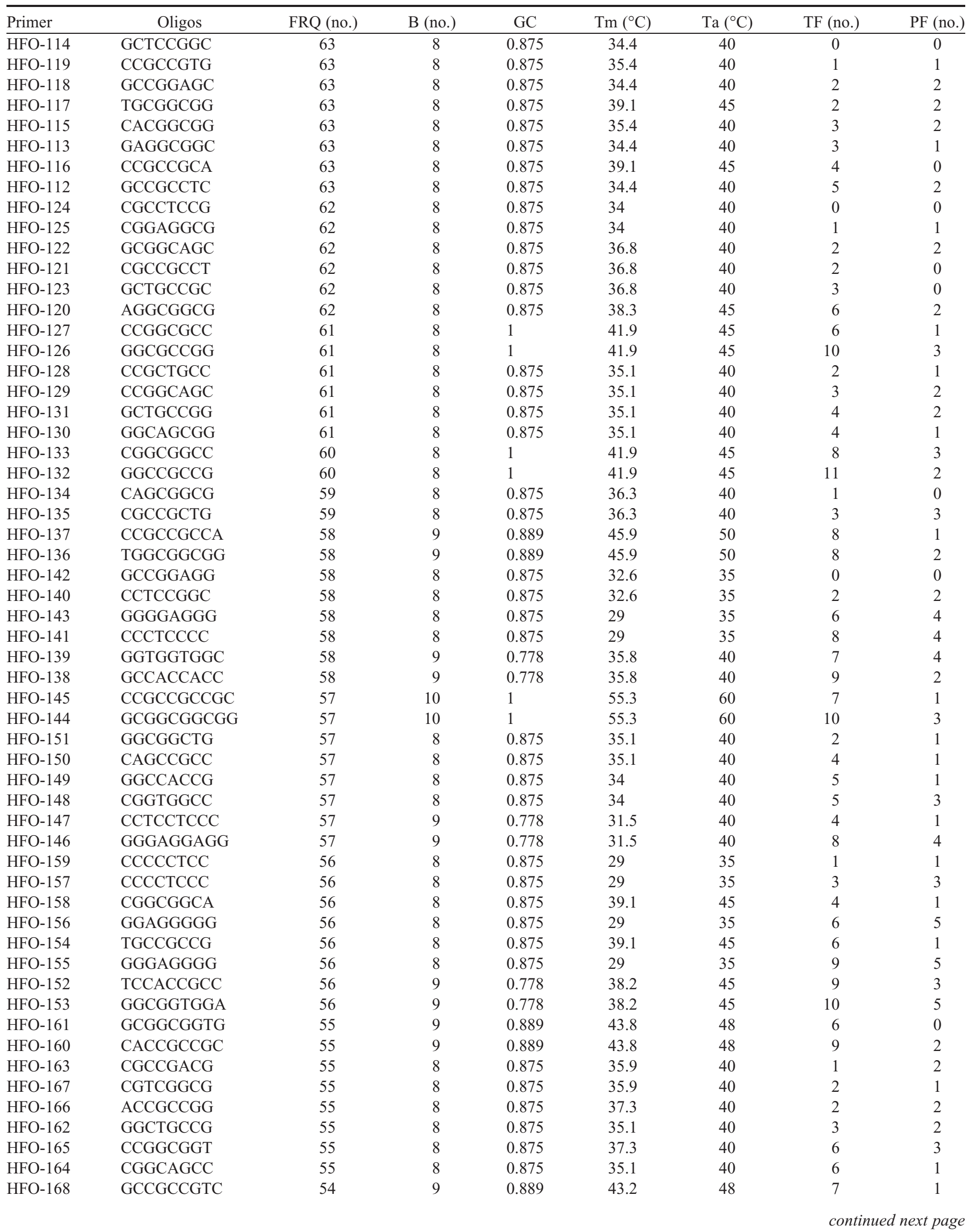


Table 1. Continued.

\begin{tabular}{|c|c|c|c|c|c|c|c|c|}
\hline Primer & Oligos & FRQ (no.) & B (no.) & GC & $\operatorname{Tm}\left({ }^{\circ} \mathrm{C}\right)$ & $\mathrm{Ta}\left({ }^{\circ} \mathrm{C}\right)$ & TF (no.) & PF (no.) \\
\hline HFO-169 & GACGGCGGC & 54 & 9 & 0.889 & 43.2 & 48 & 8 & 3 \\
\hline HFO-171 & GCCGTCGG & 54 & 8 & 0.875 & 34.7 & 40 & 2 & 1 \\
\hline HFO-172 & GGGTGGGG & 54 & 8 & 0.875 & 30.6 & 35 & 4 & 4 \\
\hline HFO-170 & CCCCACCC & 54 & 8 & 0.875 & 30.6 & 35 & 8 & 3 \\
\hline HFO-180 & GGGGCAGC & 53 & 8 & 0.875 & 33.9 & 40 & 2 & 1 \\
\hline HFO-183 & TGGCCGCC & 53 & 8 & 0.875 & 37.9 & 45 & 3 & 1 \\
\hline HFO-176 & CGCTGCCG & 53 & 8 & 0.875 & 36.3 & 40 & 3 & 2 \\
\hline HFO-181 & GCTCGCCG & 53 & 8 & 0.875 & 35.7 & 40 & 4 & 2 \\
\hline HFO-177 & GCTGCCCC & 53 & 8 & 0.875 & 33.7 & 40 & 4 & 2 \\
\hline HFO-185 & GGCGGCCA & 53 & 8 & 0.875 & 37.9 & 40 & 6 & 4 \\
\hline HFO-182 & GGCGGCGT & 53 & 8 & 0.875 & 39.1 & 45 & 10 & 5 \\
\hline HFO-187 & GGGCGGCG & 52 & 8 & 1 & 41.9 & 45 & 6 & 2 \\
\hline HFO-186 & CGCCGCCC & 52 & 8 & 1 & 41.9 & 45 & 9 & 3 \\
\hline HFO-191 & CCGACGCC & 52 & 8 & 0.875 & 34.7 & 40 & 2 & 1 \\
\hline HFO-189 & GTGGCCGG & 52 & 8 & 0.875 & 34 & 40 & 2 & 3 \\
\hline HFO-188 & GGCGTCGG & 52 & 8 & 0.875 & 34.7 & 40 & 4 & 2 \\
\hline HFO-190 & CCGGCCAC & 52 & 8 & 0.875 & 34 & 40 & 9 & 2 \\
\hline HFO-192 & CCGCCGAC & 51 & 8 & 0.875 & 34.7 & 40 & 4 & 1 \\
\hline
\end{tabular}

Table 2. The nine highly similar high-frequency oligonucleotidestargeting active genes (HFO-TAG) primers used in our experiment investigating differences and similarities in amplicons (Fig. 2).

\begin{tabular}{lllllllllll}
\hline Primer & & & \multicolumn{10}{c}{ Sequence $\left(5^{\prime}-3^{\prime}\right)$} \\
\hline HFO-105 & A & G & C & C & G & C & C & G & \\
HFO-132 & G & G & C & C & G & C & C & G & \\
HFO-154 & T & G & C & C & G & C & C & G & \\
HFO-02 & C & G & C & C & G & C & C & G & & \\
HFO-26 & & G & C & C & G & C & C & G & T & \\
HFO-38 & & G & C & C & G & C & C & G & G & \\
HFO-61 & & G & C & C & G & C & C & G & A & \\
HFO-07 & & G & C & C & G & C & C & G & C & \\
HFO-168 & & G & C & C & G & C & C & G & T & C \\
\hline
\end{tabular}

cDNA with HFO-TAG, ISSR, or RAPD primers selected in this study were as described for the genomic DNA above.

DATA SCORING AND ANALYSIS. Only clear and unambiguous fragments produced by HFO-TAG, RAPD, and ISSR primers were considered. The presence or absence of fragments was scored for the four watermelon genotypes. A $t$ test was conducted according to David and Gunnink (1997) to determine if any significant differences exist between the HFO-TAG, RAPD, and ISSR primers with respect to the number of polymorphic bands generated (Tables 3 and 4).

To evaluate the capacity of the HFO-TAG primers to produce polymorphic bands and resolve phylogenic relationships, we used HFO-TAG markers produced from the 12 watermelon cultivars and the two Citrullus PIs listed above to generate a pairwise similarity matrix using DICE coefficient (Nei and Li, 1979). A dendrogram was constructed from the similarity matrix data by applying the unweighted pair-groups method using arithmetic averages (UPGMA) cluster analysis using NTSYS-PC version 2 (Rohlf, 1993).

\section{Results and Discussion}

The development of the new generation of sequencing technologies and bioinformatics tools have opened new opportunities for genome assembly, gene targeting, and genetic mapping (Lister et al., 2009; Wall et al., 2009). In this study, we used the watermelon EST collection for searching and identifying oligonucleotides (PCR primers) that have a greater capacity than RAPD or ISSR primers to produce markers linked to active gene sequences. This approach first involves computational analysis to identify short oligonucleotides that exist in high frequency in EST-unigenes representing sequential stages of development and ripening of watermelon fruit (Levi et al., 2006a; Wechter et al., 2008). Next, we used the oligo sequence data to select for 8-, 9-, and 10-bp HFO-TAG primers with $80 \%$ to $100 \%$ GC content (Table 1). Last, we tested the ability of HFOTAG primers to amplify genomic DNA from closely related watermelon genotypes (Fig. 1) using an optimized procedure that yields highly reproducible RAPD bands (Levi et al., 1993, 2002, 2006b; Rowland and Levi, 1994).

We were able to identify 3162 oligonucleotides (8-10 bp) that are present 32 to 335 times in the 4700 watermelon ESTunigenes. These 3162 oligos can be found on the International Cucurbit Genomics Initiative (2009) website. This large number of recurrent sequences may be due to the expansion of gene families found in diploids (Bennetzen et al., 2004) and the finding from sequenced diploids that they are ancient polyploids (Kim et al., 2009). These results indicate that the EST-unigenes should be a useful source for identifying HFO-TAG primers. 
Table 3. The mean number of total fragments [TF (polymorphic + nonpolymorphic)] and polymorphic fragments (PF) produced by the RAPD, ISSR, and high-frequency oligonucleotides-targeting active genes (HFO-TAG) primers using genomic DNA of the four watermelon cultivars: Allsweet, Crimson Sweet, Charleston Gray, and Dixielee. The SD, SE, and number $(\mathrm{N})$ of primers used in this experiment. The probability values resulting from the $t$ test indicate significant differences between the HFO-TAG, and the RAPD and ISSR primers in producing TF and PF from genomic DNA of the four watermelon cultivars.

\begin{tabular}{|c|c|c|c|c|c|c|}
\hline & \multicolumn{3}{|c|}{ Avg fragments (no.) } & \multicolumn{3}{|c|}{$P$ value $^{\mathrm{z}}$} \\
\hline & RAPD & ISSR & HFO-TAG & RAPD vs. ISSR & RAPD vs. HFO & ISSR vs. HFO \\
\hline Mean TF & 4.15 & 2.32 & 5.74 & $0.0010^{* *}$ & $0.0007 * *$ & $<0.0001 * * *$ \\
\hline SD & 2.87 & 3.6 & 3.26 & & & \\
\hline SE & 0.37 & 0.36 & 0.24 & & & \\
\hline $\mathrm{N}$ & 61 & 98 & 192 & & & \\
\hline Mean PF & 0.47 & 0.89 & 1.77 & $0.0309 *$ & $<0.0001^{* * *}$ & $0.0002 * * *$ \\
\hline SD & 0.7 & 1.21 & 1.27 & & & \\
\hline $\mathrm{SE}$ & 0.1 & 0.2 & 0.09 & & & \\
\hline $\mathrm{N}$ & 52 & 36 & 185 & & & \\
\hline
\end{tabular}
respectively.

Table 4. The mean number of total fragments [TF (polymorphic + monomorphic)] and polymorphic fragments (PF) produced by RAPD versus high-frequency oligonucleotides-targeting active genes (HFO-TAG) primers using genomic DNA of 12 watermelon cultivars (shown in Fig. 3). The SD, SE, and number (N) of primers used in this experiment. The probability values resulting from the $t$ test indicate significant differences between the HFO-TAG and the RAPD markers in producing TF and PF from genomic DNA of four watermelon cultivars.

\begin{tabular}{cccc}
\hline & \multicolumn{2}{c}{ Avg fragments (no.) } & $\begin{array}{c}P \text { value }^{z} \\
\text { RAPD vs. HFO }\end{array}$ \\
\cline { 2 - 3 } Mean TF & 3.33 & HFO-TAG & \\
SD & 2.53 & 9.83 & $<0.0001^{* * *}$ \\
SE & 0.52 & 4.16 & \\
N & 24 & 0.85 & \\
Mean PF & 2.65 & 24 & $0.0002 * * *$ \\
SD & 2.25 & 6.65 & \\
SE & 0.5 & 3.92 & \\
N & 20 & 0.82 & \\
\hline
\end{tabular}

z***Significantly different at $P=0.0001$ or 0.0002 .

Here, the HFO-TAG primers produced a large number of polymorphic markers (Table 1). A considerable number of these markers might be associated with genes controlling watermelon fruit quality (Levi et al., 2006a; Wechter et al., 2008). Because a considerable number of genes associated with stress response are expressed during fruit ripening (Levi et al., 2006a; Wechter et al., 2008), the HFO-TAG primers also may be useful in screening for DNA markers associated with disease or pest resistance genes (Harris et al., 2009a, 2009b) in cucurbits and other vegetable crops. Furthermore, because these oligonucleotides exist in high frequency, they can be useful for designing SRAP primers, known to generate markers associated with gene sequences (Li and Quiros, 2003).

One-hundred ninety-two oligonucleotides that exist in high frequency (51-269 times in the 4700 EST-unigenes) were used for constructing HFO-TAG primers (Table 1). Because of the high GC content of these active-gene targeted primers, we considered the possibility that they may produce a large number of identical amplicons. To test this possibility, we conducted a PCR experiment with nine primers that are identical at seven bases and altered only in the $5^{\prime}$ or 3 ' bases (Table 2). The nine primers were tested in PCR amplification with DNA of the heirloom cultivar Charleston Gray. Each of these nine primers produced a unique DNA banding pattern (as shown in Fig. 2). We cloned and sequenced an amplicon of comparable size (800-900 bp) from each of the lanes representing the amplification products for each of these nine primers (Fig. 2). The sequence analysis showed high sequence homology (96\%-97\% homology) for the 840-bp amplicons produced by HFO-105, HFO-132, HFO-154 (Fig. 2), while each of the amplicons of comparable size produced by HFO-26, HFO-61, HFO168, HFO-2, or HFO-7 (Fig. 2) represented a unique sequence. These results indicate that although highly similar HFO-TAG primers (differing only in a single nucleotide) could produce the same amplicons (or alleles of the same amplicon), the majority of amplicons produced with these primers are unique, representing different gene sequences.

Sequence analysis using the basic local alignment search tool (BLAST) analysis for eight of the nine amplicons shown in Fig. 2 resulted in significant homology with sequences of genes encoding for cytidine triphosphate (CTP) synthetase, alanine dehydrogenase, pyridine nucleotide transhydrogenase, xylem serine proteinase, nitrous oxide reductase, or for proteins with unknown function in watermelon, melon, Cichorium intybus, or Arabidopsis thaliana. These results indicate that the HFO-TAG primers preferentially target gene sequences.

Next, we tested the ability of the HFO-TAG primers versus ISSR or RAPD primers to produce polymorphic PCR fragments between four watermelon cultivars (Allsweet, Crimson Sweet, Charleston Gray, and Dixielee) that are known to be closely related (95\%-98\% genetic similarity; Levi et al., 2001). In PCR experiments with genomic DNA of these four watermelon cultivars, 185 (96.4\%) of the 192 HFO-TAG primers (Table 1), $52(85.2 \%)$ of 61 RAPD primers, and $36(36.7 \%)$ of 98 ISSR primers produced DNA fragments (Table 1). A $t$ test indicated that the average number of fragments [including polymorphic fragments (Fig. 1)] per primer was considerably higher for HFO-TAG than for RAPD or ISSR primers (Table 3). Twentyfour random HFO-TAG and 24 RAPD primers were used in PCR experiments with 12 heirloom cultivars, one C. lanatus var. lanatus PI, and one C. lanatus var. citroides PI. The HFOTAG primers produced a higher number of fragments compared with the RAPD primers (Table 4). Twenty-three of 24 (95.8\%) HFO-TAG primers and 20 of $24(83.3 \%)$ RAPD primers produced fragments with genomic DNA of the watermelon cultivars and PIs. Overall, the 24 HFO-TAG primers produced a considerably higher number of fragments (236 fragments in total) than the 24 RAPD primers ( 80 fragments in total) (Table 4).

An additional experiment was conducted to evaluate the capacity of the HFO-TAG versus RAPD primers in producing polymorphic markers and resolving phylogenic relationships among 12 heirloom cultivars that are known to be closely related (Levi et al., 2001), and PI 203551 and PI 296341. The phylogenic 

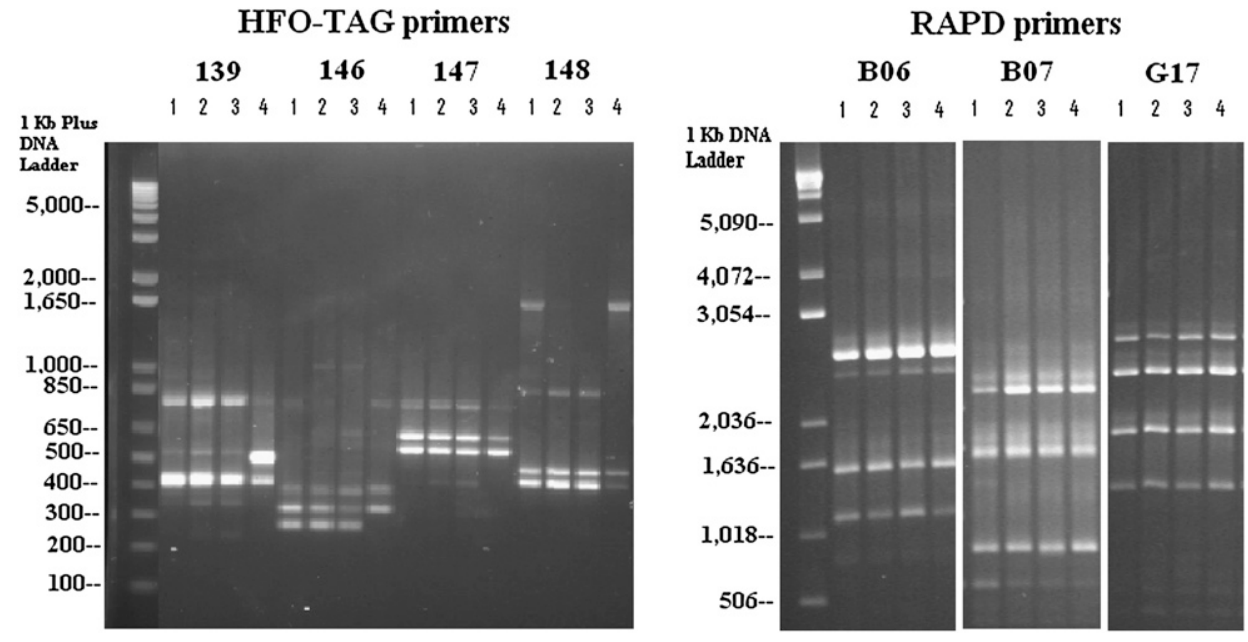

Fig. 1. DNA pattern of watermelon cultivars Allsweet (1), Crimson Sweet (2), Charleston Gray (3), and Dixielee (4) following PCR amplification with high-frequency oligonucleotides-targeting active genes (HFO-TAG) primers $139,146,147$, and 148 (Table 1) that produce a higher rate of DNA polymorphism among these cultivars compared with RAPD primers B06, B07, and G17.

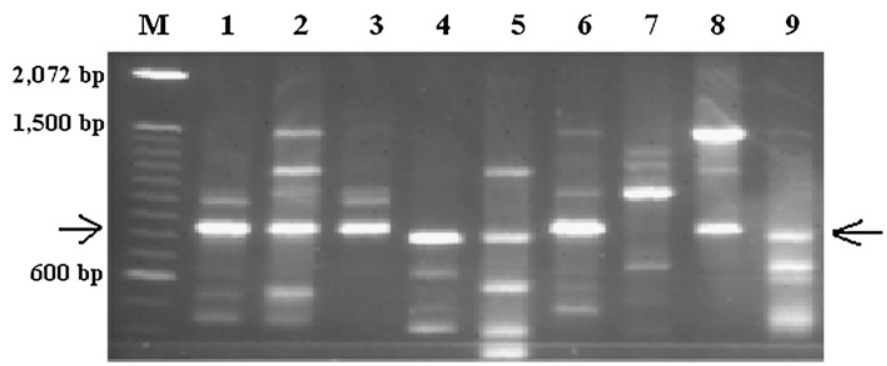

Fig. 2. DNA patterns of the watermelon cultivar Charleston Gray following PCR amplification with nine highly similar high-frequency oligonucleotidestargeting active genes (HFO-TAG) primers (Table 2). Lanes 1 through 9 are DNA patterns produced by HFO-TAG primers $105,132,154,26,61,168$, 2,38 , and 7, respectively (Table 1). Lane " $\mathrm{M}$ " is a 100-bp DNA ladder (Life Technologies, Carlsbad, CA). Arrows point to 800- to 900-bp amplicons that were cloned and sequenced.

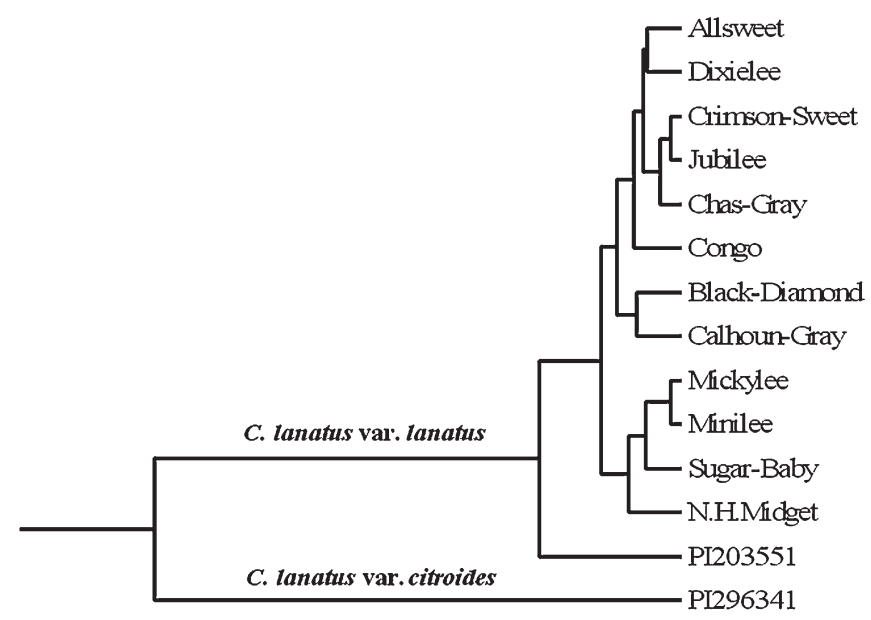

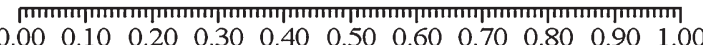

Genetic similarity

Fig. 3. Genetic similarity dendrogram for 12 watermelon heirloom cultivars and two U.S. Plant Introduction accessions produced by UPGMA cluster analysis of a similarity matrix based on 153 polymorphic markers that were produced by 24 high-frequency oligonucleotides-targeting active genes (HFO-TAG) primers. analysis based on the 24 HFO-TAG primers produced a dendrogram (Fig. 3) that is highly consistent with the fruit types and parentage data reported for these cultivars (Wehner, 1999a, 1999b, 2002). The heirloom cultivars in the first clade (Fig. 3) include Dixielee (derived from Texas W5, Peacock, Fairfax, Summit, and Graybelle), Allsweet and Crimson Sweet, who share the same parents $[$ (Miles $\times$ Peacock $) \times$ Charleston Gray], and Jubilee, which shares similar parentage background with the cultivar Charleston Gray [(Africa $8 \times$ Iowa Belle) $\times$ Garrison $) \times$ Garrison) $\times($ Hawkesbury $\times$ Leesburg $) \times$ Garrison)], and common parents with the cultivar Congo [(African $\times$ Iowa Belle) $\times$ Garrison]. Although the cultivar Calhoun Gray (Calhoun Sweet $\times$ Charleston Gray) is elongated and resembles the cultivar Charleston Gray, it is closely related to the cultivar Black Diamond (Fig. 3). Indeed, these two cultivars share a common parent, 'Calhoun Sweet', which resembles 'Black Diamond' (globular fruit with dark green skin) (Wehner, 1999a, 1999b, 2002). The cultivars grouped in the second clade are all known to produce small fruit. They include 'Mickylee' and 'Minilee' (sister lines derived from crosses between the cultivars Texas W5, Fairfax, Summit, and Graybelle), and 'New Hampshire Midget' (Favorite Honey $\times$ Dakota Sweet) and 'Sugar Baby' (an inbred selection from the heirloom cultivar Tough Sweets) (Wehner, 1999a, 1999b, 2002). As expected, the C. lanatus var. citroides PI 296341 was shown to be genetically distant from the heirloom cultivars (Fig. 3). The HFO-TAG primers produced a high number of polymorphic markers between the watermelon cultivars and the C. lanatus var. citroides PI 296341, with a lower number of polymorphic markers among the cultivars (Table 4). These results are more consistent with the parental background and fruit characteristics than the results produced by RAPDs (Levi et al., 2001), indicating that the HFO-TAG primers should be valuable in producing polymorphic DNA markers for phylogenic analysis and genetic mapping in these closely related species.

To confirm that the HFO-TAG primers are better suited to target gene sequences than RAPD primers, we tested them in PCR experiments using a normalized cDNA library of watermelon (Levi et al., 2006a; Wechter et al., 2008) as a template. In this experiment, 42 of $43(97.6 \%)$ HFO-TAG primers tested produced DNA fragments (an average of 6.44 fragments per HFO-TAG primer). In comparison, when 49 RAPD and 34 ISSR primers were tested with the same cDNA template, only $32(65.3 \%)$ of the 49 RAPD and $29(85.3 \%)$ of the 34 ISSR primers produced fragments (an average of 2.49 and 3.59 fragments per primer, respectively) (Table 5, Fig. 4). These results indicate that the HFO-TAG primers should have greater capacity in detecting active gene sequences than RAPD or ISSR primers. In addition to being useful in genetic mapping, the HFO-TAG primers may be useful in examining gene expression associated with disease resistance or in response to physiological stress, as has been shown for RAPD and AFLP primers used in conjunction with cDNA from other plant 
Table 5. The average number of fragments produced by the RAPD, ISSR, and high-frequency oligonucleotides-targeting active genes (HFOTAG) primers using the normalized cDNA library for watermelon fruit (heirloom cultivar Illiniwake Red) as a template. The SD, SE, and number $(\mathrm{N})$ of primers used in the $t$ test. The probability values resulting from the $t$ test indicate significant differences between the HFO-TAG and the RAPD and ISSR markers in producing fragments from the cDNA template.

\begin{tabular}{|c|c|c|c|c|c|c|}
\hline & \multicolumn{3}{|c|}{ Avg fragments (no.) } & \multicolumn{3}{|c|}{$P$ value ${ }^{\mathrm{z}}$} \\
\hline & RAPD & ISSR & HFO-TAG & RAPD vs. ISSR & RAPD vs. HFO & ISSR vs. HFO \\
\hline cDNA Mean & 2.49 & 3.59 & 6.44 & $0.0570 \mathrm{NS}$ & $<0.0001 * * *$ & $<0.0001^{* * *}$ \\
\hline SD & 2.57 & 2.52 & 2.76 & & & \\
\hline $\mathrm{N}$ & 49 & 34 & 43 & & & \\
\hline
\end{tabular}

z***Significantly different at $P=0.0001$, NS $=$ no significant difference at $P=0.05$.

HFO-TAG primers

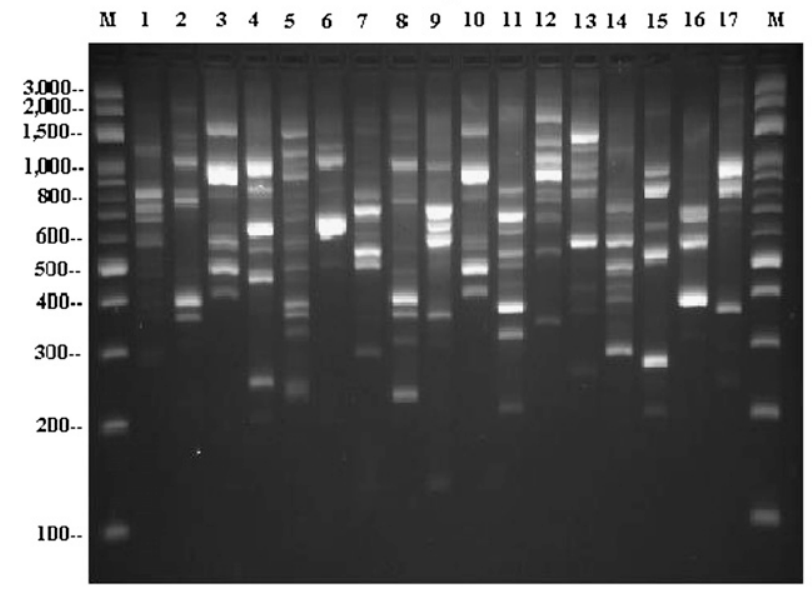

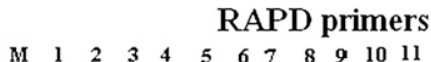

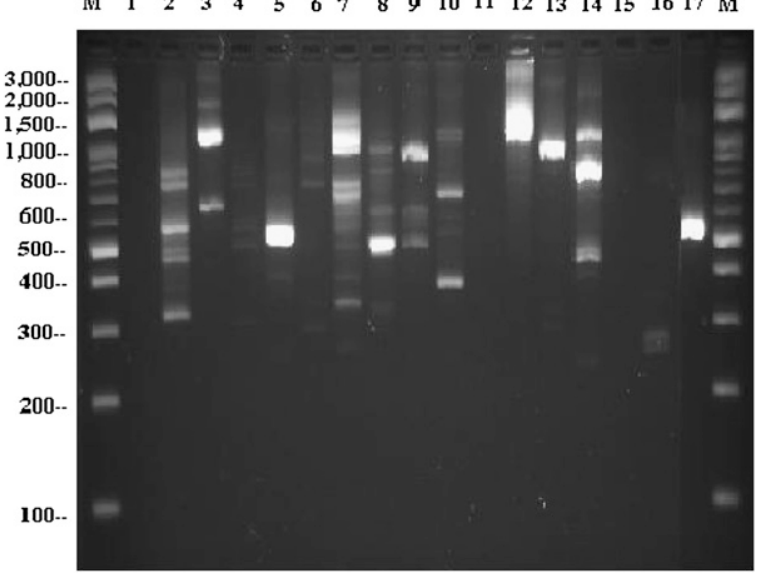

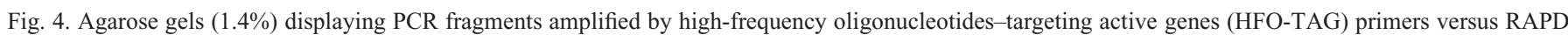
primers using a normalized watermelon fruit cDNA library as a template. The HFO-TAG primers (1-17) are, respectively, HFO-TAG 1, 2, 3, 4, 5, 6, 7, 8, 38, 39, 51, 52, 57, 58, 83, 84, 85, 86, and 89 (Table 1). The RAPD primers (1-17) are, respectively, AK03, AK04, AK05, AK06, AK07, AK09, AK10, AK11, AK12, AK13, AK14, AK15, AK16, AL02, AL03, AL08, AL12, AL15, AL16, and AL17 (Operon Technologies, Alameda, CA). The M lanes are 1 kb-Plus DNA Ladder (Life-Technologies, Carlsbad, CA).

species (Nimbalkar et al., 2006; Polesani et al., 2008). The sequencing of cDNA libraries and the development of extensive EST databases for various crop plants have facilitated the identification and development of EST-SSR (Levi et al., 2009; Sim et al., 2009) and SNP markers (Ganal et al., 2009). These markers are useful for direct targeting and genetic mapping of gene sequences (Peng et al., 2009). The procedure proposed in this study provides an additional type of EST-related markers. The HFO-TAG primers produced a greater number of polymorphic markers between the watermelon cultivars and the $C$. lanatus var. citroides PI 296341 than among the cultivars alone. Still, the HFO-TAG primers were more effective in producing polymorphic markers than the RAPD or ISSR primers (as shown in Fig. 1). The HFO-TAG oligonucleotide sequences exist in high frequency in ESTs, which comprise translated regions and $5^{\prime}$ and $3^{\prime}$ untranslated regions (UTRs). The UTRs are known to be less conserved than the translated regions, providing a plethora of mutations that can be mined for SNP markers to target important gene sequences (JiménezGómez and Maloof, 2009). It may well be that these mutations are contributing to the polymorphism detected here by the HFO-TAG primers.

Gene duplication is considered the principal force in the evolution of plants (Kim et al., 2009; Ohno, 1970). Following the duplication event, the gene replica could be mutated to form gene paralogs that encode for proteins with a similar structure or function (Gu et al., 2005). Based on this idea, it is possible that certain gene sequences have been duplicated numerous times and exist in high frequency in genomes of higher organisms. These sequences can be used to generate HFO-TAG primers for use in phylogenic analysis and genetic mapping studies.

Arabidopsis (A. thaliana) is estimated to contain 25,000 protein-encoding genes, while rice (Oryza sativa) is predicted to contain 40,000 to 60,000 genes, although this number may be an overestimation (Bennetzen et al., 2004). Hence, it is likely that the 4700 EST-unigenes used in this study represent only a portion of the genes expressed in watermelon fruit. It is possible that using a larger data set of EST-unigenes $(\approx 60,000)$, representing most of the EST-unigenes for watermelon genome, will facilitate the construction of a large set of HFO-TAG primers that could be used in producing polymorphic markers and saturating the genetic maps of watermelon and related cucurbit crops.

\section{Literature Cited}

Bennetzen, J.L., C. Coleman, R. Liu, J. Ma, and W. Ramakrishna. 2004. Consistent over-estimation of gene number in complex plant genomes. Curr. Opin. Plant Biol. 7:732-736.

David, H.A. and J.L. Gunnink. 1997. The paired t test under artificial pairing. Amer. Stat. 51:9-12. 
Ganal, M.W., T. Altmann, and M.S. Röder. 2009. SNP identification in crop plants. Curr. Opin. Plant Biol. 12:211-217.

Gong, L., G. Stift, R. Kofler, M. Pachner, and T. Lelley. 2009. Microsatellites for the genus Cucurbita and an SSR-based genetic linkage map of Cucurbita pepo L. Theor. Appl. Genet. 117:37-48.

Gu, X., Z. Zhang, and W. Huang. 2005. Rapid evolution of expression and regulatory divergences after yeast gene duplication. Proc. Natl. Acad. Sci. USA 102:707-712.

Harris, K.R., K. Ling, W.P. Wechter, and A. Levi. 2009a. Identification and utility of markers linked to the zucchini yellow mosaic virus resistance gene in watermelon. J. Amer. Soc. Hort. Sci. 134:529-534.

Harris, K.R., W.P. Wechter, and A. Levi. 2009b. Isolation, sequence analysis, and linkage mapping of nucleotide binding site-leucine-rich repeat disease resistance gene analogs in watermelon. J. Amer. Soc. Hort. Sci. 134:1-9.

Harris, K.R., W.P. Wechter, B. Lanini, E. Vivoda, and A. Levi. 2008. In search of markers linked to fusarium wilt race 1 resistance in watermelon. HortScience 43:1238 (Abstr.).

Holland, J.B., S.J. Helland, N. Sharopova, and D.C. Rhyne. 2001. Polymorphism of PCR-based markers targeting exons, introns, promoter regions, and SSRs in maize and introns and repeat sequences in oat. Genome 44:1065-1076.

International Cucurbit Genomics Initiative. 2009. Watermelon EST collection. 4 Aug. 2009. <http://www.icugi.org/cgi-bin/ICuGI/EST/ home.cgi?organism=watermelon $>$.

Jarret, R.L., L.C. Merrick, T. Holms, J. Evans, and M.K. Aradhya. 1997. Simple sequence repeats in watermelon [Citrullus lanatus (Thunb.) Matsum. \& Nakai]. Genome 40:433-441.

Jiménez-Gómez, J.M. and J.N. Maloof. 2009. Sequence diversity in three tomato species: SNPs, markers, and molecular evolution. BMC Plant Biol. 9:85.

Katzir, N., Y. Danin-Poleg, G. Tzuri, Z. Karchi, U. Lavi, and P.B. Creagan. 1996. Length polymorphism and homologies of microsatellites in several Cucurbitaceae species. Theor. Appl. Genet. 93: 1282-1290.

Kim, C., H. Tang, and A.H. Paterson. 2009. Duplication and divergence of grass genomes: Integrating the chloridoids. Tropical Plant Biol. 2:51-62.

Levi, A. and C.E. Thomas. 1999. An improved procedure for isolation of high quality DNA from watermelon and melon leaves. Cucurbit Genet. Coop. Rpt. 22:41-42.

Levi, A., L.J. Rowland, and J.S. Hartung. 1993. Production of reliable randomly amplified polymorphic DNA (RAPD) markers from DNA of woody plants. HortScience 28:1188-1190.

Levi, A., W.P. Wechter, and A.R. Davis. 2009. EST-PCR markers representing watermelon fruit genes are polymorphic among watermelon heirloom cultivars sharing a narrow genetic base. Plant Genet. Resources 7:16-32.

Levi, A., C.E. Thomas, T.C. Wehner, and X. Zhang. 2001. Low genetic diversity indicates the need to broaden the genetic base of cultivated watermelon. HortScience 36:1096-1101.

Levi, A., C.E. Thomas, T. Joobeur, X. Zhang, and A.R. Davis. 2002. A genetic linkage map for watermelon derived from a testcross population: (Citrullus lanatus var. citroides $\times$ C. lanatus var. lanatus) $\times$ Citrullus colocynthis. Theor. Appl. Genet. 105:555-563.

Levi, A., C.E. Thomas, M.L. Newman, O. Reddy, and X. Zhang. 2004. ISSR and AFLP markers sufficiently differentiated among American watermelon cultivars with limited genetic diversity. J. Amer. Soc. Hort. Sci. 129:553-558.

Levi, A., A. Davis, A. Hernandez, P. Wechter, J. Thimmapuram, T. Trebitsh, Y. Tadmor, N. Katzir, V. Portnoy, and S. King. 2006a.
Genes expressed during the development and ripening of watermelon fruit. Plant Cell Rep. 25:1233-1245.

Levi, A., C.E. Thomas, T. Trebitsh, A. Salman, J. King, J. Karalius, M. Newman, O.U.K. Reddy, Y. Xu, and X. Zhang. 2006b. An extended linkage map for watermelon based on SRAP, AFLP, SSR, ISSR, and RAPD markers. J. Amer. Soc. Hort. Sci. 131:393-402.

Li, G. and C.F. Quiros. 2003. Sequence-related amplified polymorphism (SRAP), a new marker system based on a simple PCR reaction: Its application to mapping and gene tagging in Brassica. Theor. Appl. Genet. 103:455-461.

Lister, R., B.D. Gregory, and J.R. Ecker. 2009. Next is now: New technologies for sequencing of genomes, transcriptomes, and beyond. Curr. Opin. Plant Biol. 12:107-118.

Nei, M. and W. Li. 1979. Mathematical model for studying genetic variation in terms of restriction endonucleases. Proc. Natl. Acad. Sci. USA 76:5269-5273.

Nimbalkar, S.B., A.M. Harsulkar, A.P. Giri, M.N. Sainani, V. Franceschi, and V.S. Gupta. 2006. Differentially expressed gene transcripts in roots of resistant and susceptible chickpea plant (Cicer arietinum L.) upon Fusarium oxysporum infection. Physiol. Mol. Plant Pathol. 68:176-188.

Ohno, S. 1970. Evolution by gene duplication. Springer-Verlag, Berlin.

Peng, Z., N. Elango, D.E. Wildman, and S.V. Yi. 2009. Primate phylogenomics: Developing numerous nuclear non-coding, nonrepetitive markers for ecological and phylogenetic applications and analysis of evolutionary rate variation. BMC Genomics 10:247.

Polesani, M., F. Desario, A. Ferrarini, A. Zamboni, M. Pezzotti, A. Kortekamp, and A. Polverari. 2008. cDNA-AFLP analysis of plant and pathogen genes expressed in grapevine infected with Plasmopara viticola. BMC Genomics 9:142.

Rohlf, F.J. 1993. NTSYS-PC numerical taxonomy and multivariate analysis system. Applied Biostatistics, Setauket, NY.

Rowland, L.J. and A. Levi. 1994. RAPD-based genetic linkage map of blueberry derived from a cross between diploid species (Vaccinium darrowi and V. elliottii). Theor. Appl. Genet. 87:863-868.

Sambrook, J., E.F. Fritsch, and T. Maniatis. 1989. Molecular cloning: A laboratory manual. 2nd ed. Cold Spring Harbor Laboratory Press, Cold Spring Harbor, NY.

Sim, S., J. Yu, Y. Jo, M.E. Sorrells, and G. Jung. 2009. Transferability of cereal EST-SSR markers to ryegrass. Genome 52:431-437.

Wall, P.K., J. Leebens-Mack, A.S. Chanderbali, A. Barakat, E. Wolcott, H. Liang, L. Landherr, L.P. Tomsho, Y. Hu, J.E. Carlson, H. Ma, S.C. Schuster, D.E. Soltis, P.S. Soltis, N. Altman, and C.W. Depamphilis. 2009. Comparison of next generation sequencing technologies for transcriptome characterization. BMC Genomics 10:347.

Wehner, T.C. 1999a. Vegetable cultivar descriptions for North America, list 24, 1999. HortScience 34:763-806.

Wehner, T.C. 1999b. Vegetable cultivar descriptions for North America, list 25, 1999. HortScience 34:957-1012.

Wehner, T.C. 2002. Vegetable cultivar descriptions for North America, list 26, 2002. HortScience 37:15-78.

Wechter, W.P., A. Levi, K.R. Harris, A.R. Davis, Z. Fei, N. Katzir, J.J. Giovannoni, A. Salman-Minkov, A.A. Hernandez, J. Thimmapuram, J.Y. Tadmor, V. Portnoy, and T. Trebitsh. 2008. Gene expression in developing watermelon fruit. BMC Genomics 9:275-288.

Wicker, T., S. Taudien, A. Houben, B. Keller, A. Graner, M. Platzer, and N. Stein. 2009. A whole-genome snapshot of 454 sequences exposes the composition of the barley genome and provides evidence for parallel evolution of genome size in wheat and barley. Plant J. 59:712-722. 